\title{
Teaching the Commons through the Game of Musical Chairs
}

\author{
Alekos Pantazis \\ Junior Research Fellow at Tallinn University of Technology, Tallinn, Estonia, \\ alexandros.pantazis@taltech.ee, https://www.etis.ee/CV/Alexandros_Pantazis/eng
}

\begin{abstract}
In an attempt to reinforce the role of education on the commons, this article proposes the use of non-formal education activities and experiential learning. Exploring new ways to talk to non-expert audiences about the commons, I developed an experiential education workshop called "Musical chairs as a commons" by hacking the classic musical chairs game. I have delivered this workshop to diverse audiences during the last five years, from activists for the commons and NGO members to university masters students and scholars. This article presents the stages, the form, the content and the educational approach of the three-hour workshop and discusses further steps based on participants' reflections and criticism.
\end{abstract}

Keywords: commons, teaching commons, experiential learning, non-formal education

Acknowledgement: I acknowledge financial support from the European Research Council (ERC) under the European Union's Horizon 2020 research and innovation programme (grant agreement No. 802512). I would also like to thank Vasilis Kostakis for his trust to include this workshop in his courses in TalTech University and Autonomous University of Barcelona, Konstantina Tziouma for her language editing and proofreading, the reviewers for their insightful comments, Elena Pagani, Elisavet Tapini, Maro Pandazidou, Katerina Troulaki and all participants of the workshop for their comments and participation on the actual educational process and Jose Ramos for his inspiring article.

\section{Introduction}

How can one explore and explain new ways of interaction with one another and with nature? Or, to pose another question, how can one describe water to a fish while aiming to explore new ways of swimming? Both questions are challenging as they refer either to unknown or deeply embedded concepts. Likewise: what are the processes of the commons?; what does 'sharing' mean when we mostly 'own' things?; how can one explain commons-based management of resources when there are dozens of private and governmental management systems? These are frequently asked questions among researchers, activists and advocates of the commons who often find it difficult to explain their basic concepts.

Engaging with the commons is a marginalised practice that often transcends the dominant narrative, embodying practices that are based outside of the main social imaginary of capitalism (Kioupkiolis 2019; Bauwens and Kostakis 2014). The essential characteristics of the natural and digital commons heavily differ from the profit-driven doctrine of our everyday lives. Thus, people often find it difficult to perceive the core notions of the commons. At the same time, commons are emerging in between the private and the public sphere, forming a third traction pole with radically different characteristics of social reproduction in the fields of decision-making, human relations, environmental sustainability, value production and more (Kostakis, Roos and Bauwens 2016; Kostakis and Stavroulakis 2013). If developed adequately, the commons can form a decisive 
alternative route that can help us overcome the extremely complex socio-environmental problems we are facing (De Angelis and Harvie 2014; Bauwens, Kostakis and Pazaitis 2019). Thus, being able to effectively communicate core notions of the commons can be of major importance.

This article stands as an endeavour in introducing non-expert audiences to the basic notions and principles of the commons, applying non-formal education and active learning concepts. The commons, as a socio-economic and political system, can only be understood if studied in terms of the community/resources relationship. This is why I propose an educational scenario for the commons to be met within a framework where a sense of community is created and participants are then urged to solve a resource management problem.

Any piece of knowledge, if explained merely in theory, is difficult to imprint in longterm memory. This is why the idea is to familiarise such audiences with the commons not only in theory but also in practice through processes that promote the 'learning-by-doing' concept. The approach of the workshop is that active participation evolves into constructive collaboration and later results in collective reflection and peer learning. In this process, I utilise Kolb's four-stage interaction $(2015,68)$ where the participants a) actively experiment on something, b) experience the activity, c) consciously observe and reflect on it, d) conceptualise and criticise what they observed, and, after shifting some parameters, actively experiment again.

The educational workshop under research is based on a variant of the popular game of musical chairs. This game is also known as the "chair game", "chair dance" or "going to Jerusalem" (Padula 2009, 410-411) and is known under similar concepts in different countries; as for example "Sandalee" in Iran, "Karrige" in Albania, "Sapoti" in Eritrea, "Sillas Musicales" in Peru or "Il Ballo della Sedia" in Italy (You Are What You Play 2020). It is practiced in Europe, Asia and America and has its origins in the 14th century, in a similar game that has been played in southern India named "Khambada Gadane" (Padula 2009; Kamat 2009). In Khambada Gadane, "players clutched available pillars in temples or large mansions as soon as the song ended or a cue was given" (Kamat 2009). Similarly to how Kamat describes the game of seven centuries ago, Alessandra Padula describes the current version of the game in Encyclopedia of Play in Today's Society $(2009,410)$ :

the players are counted and a number of chairs one fewer than the number of players is arranged, usually in a circle or in a line back to back [...] at the start of the game, the players stand in a circle outside the chairs. A nonplaying person, usually an adult, plays recorded music or a musical instrument. While the music is playing, the players in the circle walk, march, or dance around the chairs. The music suddenly stops, and each player must rush to one of the chairs and try to sit down as quickly as possible. Of course, there is one less chair than there are people, and one player is always left standing. This person is eliminated and play continues until one player remains.

There are slightly different versions of the game: in Albania, participants are found to be standing on pieces of paper named "musical islands" with one piece at a time being removed; in Italy a "musical broomstick" held between the legs has to pass on among participants and is dropped out when the music stops; and in Peru "a balloon is passed beneath squatting bottoms" (You Are What You Play 2020). Moreover, there is a cooperative version of musical chairs where chairs are removed, yet participants are asked to sit by sharing chairs or to sit on someone's lap (Padula 2009, 411). 
According to Padula, the game practices visual, auditory, spatial and kinaesthetic abilities but only the cooperative version is considered to enhance the "ability to interact effectively in society, solving social problems and cooperating with others" $(2009,410)$. Thus, apart from the kinaesthetic skills, one might well ask what the social skills enhanced through the non-cooperative versions of the game are. On closer inspection, the 'classic' versions of the game of musical chairs fortify resource competition, individualism among players and possession via exclusion of the have-nots. This comes as no surprise, as McCabe observes, since board games had often reproduced dominant concepts, amplified damaging stereotypes and even contributed to colonial and neo-colonial ideology (2018, 647). In order to support his argument, McCabe refers to two well-known board games, Risk and Civilization, where the conquest and control of foreign territories and people "serve to normalise" colonial practices $(2018,647)$. Having its roots in the distant past, the musical chairs game seems to reflect some of the most dominant values of today's society. We laugh when excluded from the chairs because it is just a game, but if it were water, food, livelihood or shelter we had lost because somebody else got there before us, we wouldn't be laughing and we wouldn't consider it a game at all. It is difficult not to wonder about the social reflexes, subconscious norms and power relations that are reinforced through this game. But, as strong as the lessons of the classic game are, so can the lessons conveyed be if we hack the game based on different principles.

This workshop can enable participants to realise that plenty of the commons' applications are featured in their everyday lives, and they can also touch upon the ideas of researchers of the commons like Elinor Ostrom (1990/2015), David Bollier and Silke Helfrich (2019), Massimo De Angelis and David Harvie (2014) or Ugo Mattei (2012). Frequently, people may not even be aware of their exposure to aspects of the commons. To convert such ignorance to awareness, the game is deliberately designed to make participants experience a transition from the exclusive form of the classic musical chairs game, to an inclusive, communal variant of the game. After experiencing the commons through the game, participants are introduced to some basic theories about the commons and are then called to combine experiential and theoretical input by finding commonsbased solutions within real-life case studies. The ultimate aim of this article is to investigate non-formal education and Kolb's learning cycle in understanding complex concepts like the commons.

The rest of the article is organised as follows. I begin with an overview of educational approaches that have influenced this workshop. Then, I review a few cases where the game of musical chairs has been adopted as an educational practice. I continue by giving a detailed description of the six stages constituting the workshop and, finally, I reach conclusions based on participants' reflections, and discuss future challenges.

\section{Active Learning and Teaching Commons}

Yoder and Bicksler were concerned about how to teach early-career students concepts of commons and institutions $(2012,364)$. As they put forward, there are plenty of academic programmes that contribute to research on the commons, but very few university courses that teach students about the commons. In their teaching project, USbased students were involved in a programme in Thailand to learn about "commons resource-dependent communities control and access regarding coasts, forests and rivers". Later on, they "transferred this learning to other, more familiar settings [that] are built into the field-based courses" (Yoder and Bicksler 2012, 363). Their case can be looked into from a political ecology perspective and within a framework they called "institutional arrangement" by which they aimed to guide the students' inquiries in the fieldwork. They used the term "institutions" (as introduced by Ostrom) as "sets of rules, 
norms and strategies that formal and informal organizations use to govern resource ownership and access" (Ostrom 1990/2015, 369). After experiencing how communities manage their common resources, students were asked to apply acquired knowledge into their familiar contexts.

From a broader perspective, what differentiates non-formal from formal education is that the latter's focal point is hierarchical, often teacher-centred or knowledge-centred, advocating standardised knowledge dissemination; by contrast, non-formal education highlights students' participation in the learning process, putting the students' experience in the centre (Ngaka, Openjuru and Mazur 2012, 120; Blikstein 2013, 3). While informal education features an incidental accumulation of experiences or skills stemming from daily interaction with an environment, non-formal education stands as something between formal and informal (Dib 1988, 2-6). In fact, non-formal educational activities can be described as open, creative and resilient to changing conditions and individual needs.

Putting aside formal schooling and university experiences, which are often seen by the students as monotonous and suppressive, non-formal education programs are usually welcomed by those who are genuinely interested in acquiring knowledge and skills, often outside institutions. Thus, a profile of education as self-committed involvement and active participation usually leads to a more effective learning process. This is why such methodologies are particularly helpful when the task is to immerse students in new concepts, such as the concepts of the commons.

As many significant figures of educational theory such as Maria Montessori (Wentworth 1999, 44; 100), Lev Vygotsky (van der Veer 2007, 46) and Paulo Freire (2000, 82-86; Freire et al. 2001, 25-30; 78) have pointed out, learning through experience is a key concept that renders the active involvement of participants crucial. In the same vein, Jean Piaget established the constructivist learning theory (Kohler 2008, 256-257; Ackermann 2001, 3-4), while Papert characterised learning as "building knowledge structures" (1994, 207), making collaboration, communication and creative learning essential. Participants engage in a problem-solving process, which finally empowers the educational objectives (Ackermann 2001, 4-5). By contrast, in traditional education approaches, students cannot consider themselves as producers of knowledge. Moreover, in constructionist non-formal education programs, the role of the teacher is reshaped to that of a facilitator and guide who encourages students' self-motivation in the learning process (Cavallo 2000, 771). Under this perspective, experiential education, when put together with constructionism, utilises embodied memories from real-life experiences as 'building blocks' for learning that, linked with the designed and facilitated path of problemsolving or whatever educational trajectory the group follows, aims to connect experience and knowledge into new building blocks.

\section{The Musical Chairs Game in Education}

The analogy of musical chairs was first used in sociological research by Waldinger (1987). He likened the game to the economic integration of different ethnic migrant groups in New York's economic life. While seeking why various ethnic groups were successfully acquiring certain positions in the economic life of the city, he saw some structural determinants in this process. More specifically, he pointed out the race-based social structure of a country which led the people to be classified according to ethnic and racial characteristics, putting the dominant white culture in first place and the 'outsiders' towards the end. In such an order, migrants will find vacancies in positions that non-white workers would accept. This process puts migrants who want to be assimilated in the city's economy on a waiting list. Provided that this process may take years for newcomers, they usually follow their own community networks, forming ethnic concentrations: "niches" 
(Waldinger 1987). Based on similar considerations, Rath (2000) investigated how Waldinger's empirical foundations could be built on in his own case study in Amsterdam. He examines whether the formation of "niches", as Waldinger termed them, exists and whether the migration patterns that resembled the game of musical chairs could be applied in a similar case in Amsterdam.

It seems that Susan R. Takata (1997) is the first documented person to implement the musical chairs game for educational purposes. In her article she describes how she implemented this game with a view to introducing the sociological theories of Durkheim, Marx, Weber, Lombardi and others to her students. As her inspiration, Takata (1997, 200201) mentions Robert Fulghum, who revised the musical chairs game into inclusive practice instead of exclusive as in the original version. Based on this idea, Takata hacks the game, asking students to sit on someone's lap so that nobody is excluded from the game. Then, using Dewey's learning-by-doing approach, she creates links between the students' play experience and the sociological theories to be taught by urging students to connect their reflections on the game with sociological theories. She uses this game to introduce students to the basic sociological theories that she further analyses during her course, as well as to showcase that cooperation, rather than competition, can function as a means of accomplishing a goal. Among other reasons, she used this game in order to discuss issues like group-processing skills, the challenges of critical thinking, problemsolving and process-based learning (Takata 1997, 202). In Takata's course on introductory sociology, the chairs game "introduces sociology as a discipline and illustrates how fun the discipline can be in helping us to understand both global perspectives and our everyday life" as "it is an effective technique for shifting the classroom focus from competition to cooperation" $(1997,202)$. She beautifully highlights the essence of experiential education by referring to the old Chinese proverb "Tell me and I forget. Show me and I remember. Involve me and I understand" $(1997,204)$.

Being close to Takata's approach, yet unaware of her work, I was concerned about finding experiential ways to teach commons-related concepts. For the last five years, I have been advocating for the commons and introducing their concept to academic and activist audiences. As a result, I have had first-hand experience of the conceptual difficulties faced; at the same time, however, talking about these difficulties has provided me with a thriving space for experimentation. When I read Jose Ramos's article entitled "Reversing the Game of Musical Chairs: the Future of Work" (2016), I imagined transforming the article's main idea into an actual experiential educational game. Ramos compares the rules of the classic musical chairs game to capitalism and proposes the reversal of musical chairs as a model for the commons-based economy. As he articulates:

Most of us are so busy playing this game, we hardly realise that we must step away to play a different game altogether. This new game we can call the "commons economy", in which one person's gain is not to the exclusion of the other, but rather considers and nourishes a whole social community and whole ecological system (Ramos 2016).

Based on the two different musical chairs games that Ramos envisioned, I developed an experiential education workshop named "Musical chairs as commons". In the following sections, I describe the process of this non-formal educational tool that advocates for the commons, analyse the remarks that came up during practice and propose further steps. 


\section{Presentation of the "Musical Chairs as a Commons" Workshop}

The majority of people are aware that the game of musical chairs is played with a number of chairs and music. Participants walk or dance around the chairs, and when the music stops, the one that didn't find a place to sit is expelled. The rules of the second version of the game reflect a strong intention to provide participants with cues about the notions around the practice of commons: when the music stops everybody has to find a way to be seated and nobody is expelled. This control over the conditions of the mainstream version of the game blazes the trail for the attainment of the study's objectives. It was hypothesized that the experiential style of learning would have a positive correlation with active participation and, at the secondary level, that participants' interaction with the commons-based form of the game would be preferred.

This workshop is a structured experiential process communicating the very basic concept of the commons. In particular, it aims to bring to the attention of a general audience a new mode of social forms and production that is based on the commons. It is a workshop that facilitates how people can acquire knowledge and form an opinion about the commons from experience. Given that the workshop is developed upon a game, participants have to actively perform certain procedures. Two different procedures direct the workshop: in the first, participants play the traditional version of musical chairs whereas in the second they play the revised version of the game. The transition from the first to the second game process enables the comparison of the two versions. It is therefore anticipated that participants will be overrun with emotions that differ, yet are analogous to each procedure. The comparison of the two procedures is evaluated individually by each participant based on the internal emotions and thoughts evoked during the whole process, but interpreted collectively in constructive and open rounds of reflection dialogue that take place among participants after each round and at the epilogue of the workshop.

The whole workshop is not solely inspired by the game but also developed on the basis of an experiential style of learning. This means that the workshop is divided into integrated, successive stages that participants go through in a fixed order. Play, reflection, lecture, group work and presentation are the basic learning 'bricks'.

It should be mentioned that the workshop was held ten times involving, among others, masters students, NGO members, artists and environmental activists; the procedures were followed in the same manner, though slightly enriched by gained experience in the last versions. The workshop has six stages: in the first introductory stage, we clarify to the participants what experiential education is about and how a game can also be a means to education. Thus, people are motivated to participate mindfully. In the second stage, participants play the classic version of the game and, in each round, stop for a collective reflection where they are invited to share thoughts and feelings. In the third stage, participants play the hacked version of the game, also with intervals for reflecting. The fourth stage comprises a final big round of discussing and reflecting. The fifth stage includes an introduction to Ostrom's principles, and to some more thinkers of the commons, and at the sixth stage, participants are divided into groups undertaking the task of forming management rules based on a real-life case of co-managing a shared resource. At the end, groups present their management rules and their reasoning, and a final roundtable discussion takes place.

\subsection{Stage 1: Introduction}

At the outset of the workshop, the facilitator begins with a short introduction of the main objectives and structure of the game and the addition of some information about the characteristics of non-formal education. The latter is included because few people are 
familiar with such types of activities, so an explanation of why this is not a 'time-wasting game' but a structured educational experience and an encouragement for active participation is needed. Consequently, the facilitator outlines the first activity in which the participants will join.

Most people know the musical chairs game from their childhood, yet explaining the rules of the game to the participants ensures maximum inclusivity and the proper conduct of the game: for instance, participants' dancing instead of walking is not always granted, so a preliminary explanation helps to foster it. Also, a short prompt to think of the chairs as a resource like bread or water is made. This stage confirms conscious and voluntary participation as whoever does not want to participate is free to be an observer, which is also a role that may be utilised fruitfully. In turn, this voluntary consent to investigate the nature of the workshop enhances participants' openness to active experimentation.

\subsection{Stage 2: Classic Musical Chairs}

In the first form of the game, participants are asked to dance around the circle of chairs; when the music stops they have to sit, knowing that in each round there will be one chair less than the number of participants and that whoever is not seated will be excluded from the game. The setup of the chairs looks inwards in an effort to facilitate communication and interaction.

Engagement takes place within a predetermined setting: chairs and music constitute the basic instruments of the procedure. While playing, although participants seem to get carried away by the melody of the music, they are often observed to be staring at the chairs, perhaps out of fear of failing to take a seat when music is over. With either competitiveness or fear of failure driving their motivation, participants seem to grow more and more committed to the task as time goes by.

The participants left standing when the music stops are expelled from the game by the facilitator. Sometimes, a strict attitude towards the loser is intentionally adopted, so that greater emphasis is placed on the fact that this type of game is based on competition and exclusion. In each round of the game, a reflection circle follows on how participants acted and felt; i.e. the feelings of an excluded person or the reason s/he didn't find a chair are discussed.

Each elimination signals the initiation of a new round with fewer chairs. As soon as the music stops and one person is driven away from the game, the rest of the participants prepare for the next round. The more participants leave the game, the more focused on the game those remaining become. In every round someone is expelled from the game and a short interval takes place in order for participants to reflect. Some of the explanations were "it is his fault, he was too slow", "he was aware of the rules", "he was lazy".

Attention must also be paid to what the expelled participants stated in terms of how they felt and how they reacted: "I don't like being competitive, so I prefer to let others sit", "at the first rounds, I caught myself cheating - dancing but staring at the chairs - so I decided to be more relaxed". Others confessed that they expected to feel a lot worse for being eliminated than they actually felt: "while dancing around the circle the prevailing emotion is anxiety, now I feel relieved of the victory burden, it's better observing from outside".

In this view, the classic mode is a typical power game with players striving to survive on antagonism. It thus cannot be ignored that, in order to handle the sharp competitive atmosphere, participants decide to approach the game through antagonism and they put efforts into staying alert for the elimination moment while they -mostly pretend to dance around the circle. When the game is over, the whole group of participants (along 
with the excluded) is gathered back into the circle for final discussion and observations. People's comments are frequently concerned with their feeling stressed and nervous by the competition, or complaining that many are not really dancing. Some say that they enjoy playing because the rules are clear while others that they prefer to lose than having to act in such a competitive context.

\subsection{Stage 3: Musical Chairs as Commons}

In this stage, both the purpose and the setting of the game are switched. The main modification is that even though in each round chairs are still decreasing, no participant is excluded and they all have to find a way to be seated. Participants, once it was explained to them that they had to cooperate in order for all to have access to and enjoy the resources, started brainstorming. In this form of the game exclusion is no longer part of the procedure and the new challenge is that the community of participants have to mind-shift and treat chairs as a common resource. They are encouraged to think of chairs as a vital resource like bread or irrigation water. When the music stops, participants are given some time to think and discuss so that they can come up with inclusive solutions that by definition stand against ostracism and supremacy tactics. When all participants are seated, this means that they have made good use of their common resources.

However, participants were purposely not introduced to the ideas of commons so that they would be unbiased in order to first experience the commons-based game without preconfigured schemas or prejudices. Thus, they could reflect freely on what they would experience while playing, and only after this stage would they learn more about the commons and make links with their recent experience and prior knowledge.

The game begins and participants appear to be more relaxed. When the music stops, instead of running towards a chair, participants kindly offer their seat to another person and try to arrange the chairs so that no one is standing. Every round is followed by reflection. Chairs are getting fewer and fewer and participants remain in the terrain trying to find out ways to fit (Figure 1).

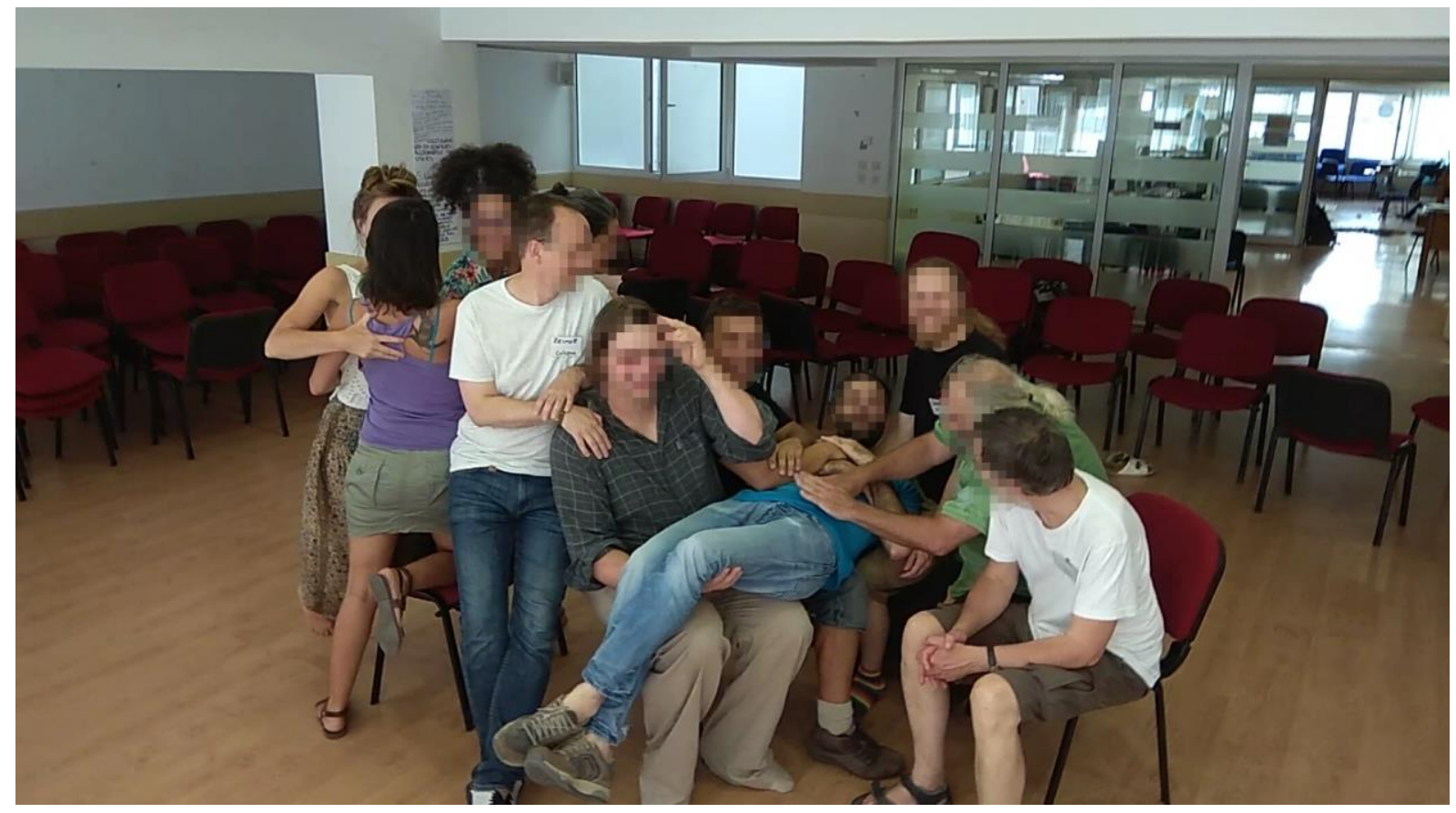

Figure 1: Photo of players of "Musical chairs as commons" workshop inventing ways to be seated (Author's personal archive) 
After each round, a short discussion among participants about reflections on the second version itself, and the differences between the two versions, takes place. How do participants feel in the absence of competition? What does sharing a common resource mean in practice? What kind of collaboration, power relations and ideas took place and what kind of difficulties occurred? Such questions are posed during the reflection intervals.

The majority of participants agreed on feeling considerably less anxiety through knowing in advance that no one would be expelled, even though at some point there could be 15 people trying to fit on 4 chairs: "I was acting more loosely since I knew that I wouldn't be excluded or deprived of the resource", "I was feeling safe while dancing since I had put faith in the community". According to other reflections: "I felt like everyone was enjoying the game instead of being pressured by the condition of exclusion", "I noticed that while dancing we were also interacting with each other". At each round, participants share ideas regarding novel solutions on how they can all fit on the chairs. Some participants devoted time to brainstorming functional solutions, while others just enjoyed dancing.

Participants usually join the chairs in order for more people to fit. They also come up with innovative ways to do so such as offering their knees as a temporary place to sit or even removing the chair's back, using it as an additional surface for sitting. The sociological characteristics of this procedure are rich. For example, females and males have the tendency to cluster; some participants try to organise the rest of the people or discuss solutions while others are just dancing; and people wonder about the actual state of sharing, which does not always mean that you get as much as you do in the state of owning.

\subsection{Stage 4: Reflecting}

Apart from the intermediate reflection sessions, the musical chairs game ends and the workshop continues with an overall reflection procedure. Participants openly express their thoughts and feelings and share opinions they formed after being exposed to the two different situations. By experiencing two variants of the same game, participants come to understand aspects of individualism - in the first version - and communalism - in the second version - and the practices of capitalistic and commons-based approaches that each game encapsulates. After they had compared the procedures corresponding to each of the two systems, participants were surprised by the divergence in emergent values. They also contrasted their prior knowledge or preconceptions to what they had experienced. Many mentioned that the fact that this classic, timeless children's game could be associated with notions of competitiveness, inequality and self-interest had never crossed their minds. On the critical side, some experienced commoners noticed that the game is not needs-driven but resources-driven, downgrading the community's role, or they questioned authority: "Why are the chairs reduced? By whom?" (referring to enclosures of the commons); "What can we do so that our resources are not depleted? Can we build new chairs?". Criticism is usually voiced concerning the focus of the game, namely that it shouldn't be so much oriented toward resources but that the group should focus on different needs for accessing the resource that each participant might have and on the collective governance model. Of course, the interpretation of all participants' comments needs to be carefully taken into account.

Up to now, this workshop has been able to stand alone since the experience and reflections formed have mobilised a rich tapestry of emotions and thoughts. However, it can also serve as a preface for introducing approaches to theories about the commons that reflect on the ways in which people collectively manage their needs. As has already 
been mentioned, Ostrom's theory and other theories about the commons were purposefully not introduced before participants had been given the opportunity to first live the actual experience unbiasedly, then to reflect and think for themselves based on both their new experience and their prior knowledge and thus create their own knowledge 'bricks'. Only then are they introduced to theories about the commons, before reflecting again.

\subsection{Stage 5: Introduction to Theories about the Commons and Case Studies Group Game}

The reflection phase ends with a short break. In the new phase, depending on participants' experience with the commons, the main aim is to introduce and explain the basics of Ostrom's theory and/or other theories about the commons. This stage combines the experience gained with new theory input, thus transforming the already formed mosaic of embodied and abstract information into a reasonably connected puzzle of knowledge.

Ostrom's theory and principles are significant for teaching about the commons. Ostrom was a leading figure in theorising the commons in economic sciences with her Nobel-Prize-winning study into the successful collective management of natural commonpool resources from the early 1960s. She examined hundreds of cases around the world where local communities managed natural common-pool resources. Ostrom's magnum opus "Governing the Commons" challenged Hardin's "tragedy of commons" theory (Ostrom 1990/2015) via her collected empirical evidence, proving that communities had self-governed their natural resources in a sustainable way for centuries, just the opposite of what Hardin proposed. The term "common", for Ostrom, merely refers to a resource shared by a group of people. According to her, communication is vital for the lifespan of a community that self-manages a natural resource. She believes that when a problem exists, members of the community will find ways to solve it through communication and interaction. On the other hand, she acknowledges that not all commons are successful and therefore that they may be dissolved. In order to understand why some commons are successful and endure over time while others dissolve, she developed the "institutional analysis and development framework", where she aimed to determine universal patterns in an attempt to explain the rules of successful commons. She defined these rules as "operational rules", "collective-choice rules", and "constitutional-choice rules" (Ostrom $1990 / 2015,51 ; 52)$. Moreover, she proposed a set of 8 design principles $(1990 / 2015,90)$ that are significant in order to achieve successful, sustainable common-pool institutions. These are presented and discussed with the workshop's group.

The commons are a triad consisting of a resource, a community and the management rules that the community forms in order to co-manage this resource (Bollier 2014, 18). Putting it differently, the triad of commoning consists of "Social Life, Peer Governance, and Provisioning" (Bollier and Helfrich 2019, 93), thus is mainly about "creating and maintaining relationships" $(2019,93)$. Tomašević adds that the commons can be seen as the "social practice of governing a resource" through the institutions that a community of users creates (Tomašević et al. 2018, 74). Up to now, together with the participants, we have created an experience of how it can be to compete for or to share a resource, and have analysed some theories on successful management principles for natural commons, but we have slightly disregarded the actual process of commoning, which is where the triad shines: the actual deliberation among community members for the creation of collective rules. So, in order to put into practice everything that has been mentioned so far, participants split into groups consisting of 4 to 8 persons. The purpose is to focus on real-life problems and resolve them based on Ostrom's set of principles and the experience from the musical chairs game. Each group chooses to deal with a case and 
has to discuss and design a set of rules in order to manage the resource. So far, we have used three cases, described below. In some instances, it is preferable to use only one case in order for the output of all groups to be easily comparable at the final roundtable discussions.

Case studies include:

- An off-grid town decides to create a wind power energy cooperative. After collectively choosing the size and installation spot of the wind turbines, residents have to set energy distribution rules and any other management issues. Participants are given, in the form of plastic cards, the annual amount of produced electricity, which is less than their total demand, and a list of the consumption rates of different needs. Additionally, participants are provided with a two-axes diagram that facilitates the discussion about their needs: the horizontal axis describes whether the need is a necessity or a luxury and the vertical axis depicts whether the need consumes low or high amounts of energy. Participants then have to analyse and agree on actions and rules for the best management of the available electricity among them.

- A town that depends on fishing in a lake needs to come up with rules about regulating the amount and type of fishing based on the fishing area, the quality of the fishing waters and the breeding periods. Participants are given the annual estimated amount of fish (which is less than their total needs), a list of needs for each fisherman and their different fishing tool capabilities.

- An agricultural village needs to come up with rules about regulating the amount of irrigation water among farmlands. Participants are given the annual amount of water that comes from the river, which is less than their total needs, a list of needs for each farmland, and the order in which the farms are located on the slope.

Based on their background, the reflections that emerged during the game and the discussion about commons, participants are now called to synthesise their overall experience and come up with community rules. After a while, each group presents its management rules and then a final round of reflection and discussion takes place. Some of the proposed ideas are: "Assess the needs of the community and then compare them with the available resources, don't start with the availability of resources", "Don't take scarcity for granted - instead, look for solutions that can meet the needs of each community", "respect all community members' needs", "reduce consumption to meet the available resources", "use technology to monitor resource consumption", "prioritise community needs and agree on the ethical background of the rules", "merge activities (e.g. cooking) in order to consume less resources" or "distribute the resource to each member according to his/her needs rather than dividing the available resource".

The community, having experienced how a rule-imposing game like musical chairs can be turned into a community-empowering game, is now asked to suggest rules to frame real-life problems. This initiative aims at conveying the genuine principle of the philosophy of the commons: each community acts as a self-governing body, making decisions and establishing its own rules. This process, as analysed by Baur, is a way to reflect on how players behave in dilemmas related to the commons and how this influences the sustainability of resources (Baur, Liechti and Binder 2014, 658-662). Participants make final observations, and the facilitator of the workshop comments on the whole procedure and makes connections between theory, the case studies and the musical chairs game, or between the work of Ostrom and other researchers' work related to the commons. 


\section{Discussion}

The conception of this educational workshop was inspired by the will to best communicate the essence of the commons.

First, the classic musical chairs game stands as a representation of the dominant system. Provided that in capitalistic environments, community members' motivation for productivity is based on the pursuit of personal profit maximization and not on the contribution to a shared resource, we come to the conclusion that such an environment is produced in the first version of the game. The chairs, here, are treated as essential assets: if you don't have one, you are out of the game. The participants, being informed about the rules of the game, are actually pushed to become individualistic 'doers' who strive, in each round, to obtain an asset. Over time, the community is divided into two sub-communities: those who possess commodities and are seated, and those who don't and remain upright. Due to luck, or given that some participants are in a more privileged position than others, for example, possessing the ability to move faster or having larger bodies, the generation of competitive emotions and tension is unsurprising. What is most noticeable is that the exclusion stipulation and the reflection on it usually transforms the game into a deeper process rather than just another icebreaking activity.

The second, 'hacked' version of musical chairs stands as an experiential reflection of what a system based on the idea of commons could look like. Here, participants are once more members of a community: this time, though, chairs have to be managed as a common resource. Now, with just a small shift in the rules of the game, participants discuss and collaborate, offer their seats, smile at each other and join their efforts in producing innovative ideas to overcome scarcity.

The classic and the commons-based game are radically conflicting with regard to their overriding aim: the former aims at cultivating competitive intentions that would inescapably give rise to inequalities between members; the latter aims at strengthening members' relations by inclusion and collective practices.

In our case, the two games, apart from their goals, differ in their processes, too. In the commons-based game, the elimination process is out of the question, even though resources are scarce. In addition to this, the pressure on the scarce resources increases at each round as chairs become fewer but participants remain the same (in the classic game, the number of participants is one greater than the number of chairs, and participants and chairs are reduced at an equal rate, so the competition is always for one chair). As the resources are not enough for all participants, they start discussing and collaborating in finding solutions to their common problem, for example: connecting two chairs, thereby creating space where more than two people can sit i.e. mutualising common resources for the benefit of the community; or sitting on top of one participant's knees i.e. taking personal responsibility for helping the community; or removing the chair's back and using it as a sitting surface i.e. community innovation.

In order to bring out the experiential, embodied knowledge that is created in the game, participants follow a variation of Kolb's learning circle $(2015,68)$ : in each round, there is a pause for reflection. Participants formulate extremely insightful observations. "I dance much more relaxed than I did in the previous game version", "It's nice to know that I am not going to exclude anyone", "I have time to enjoy the music while other people try to find ways to share the chairs while dancing: finally there is room for laziness!", "Why do we lose chairs?; Is somebody destroying them or excluding us from our common resource?; should we question authority?", "We should take care of the cause that reduces our resources", "We should take action, building chairs or repairing them, but should the ones that will do the maintenance sit more?", "Men and women tend to share chairs with people of the same gender, why is this happening?", "Sharing the same seat 
with 3 people is not as comfortable as before, sharing is nice but demands more effort", "Maybe we should employ a form of rotation to make sitting less tiring" are some of the reflections that are often heard. Participants experience the remarkable difference between the two versions of the game, which leads to comparisons between the two processes and enforces the primary understanding of how commons-based management functions around a tangible resource.

Even though the workshop took place in different conditions involving various groups of participants, everyone managed a smooth and quick transition to the spirit of commons and very few complained about feeling oppressed for having to share. When something like this happened, it was discussed with the whole group and resolved. For example, in one case the group agreed to give to the person that disagreed with the co-management of resources one chair for himself/herself and this initiated discussions regarding the extent to which a community should respect individual freedoms and vice versa. Eventually, most community members enjoyed the sharing of resources within the framework of a free and indiscriminate resource-availability (even within a resourcescarcity situation), having practiced their communal creativity instead of personal competitiveness. However, we have to make clear that experiencing those practices, emotions and embodied interactions is at the most an elementary glance of what the commons might be. Nevertheless, from an educational point of view, I argue that there is a qualitative leap: once you've lived the experience, it is much easier to understand even more complex concepts about commons, and much harder to forget.

However, a number of identified weaknesses of the workshop and additional ideas that are either mentioned by participants or developed by the practitioner leave plenty of room for improvement, the most interesting of which are discussed below.

Most importantly, the experiential part of the workshop is resource-oriented instead of community-driven. It is difficult for a game that is based on possessing or sharing a chair not to focus on the resource.

Although from an educational perspective it can be argued that an individual's first ever introduction to the commons has to be as tangible as possible, a commoner would argue that we should place the focus on the process of commoning rather than on a narrow resource management issue. Ostrom's "closed" systems of commons management refer mostly to natural resources managed by geographically small, defined groups of people and, as it may well be argued, today's cases of commoning are much more complex, including various localities, digital sphere, power dynamics, social struggles and governance rules that diverge greatly from Ostrom's 8 principles. For a more detailed discussion, please see the excellent description of the evolution of the notions on the commons by Tomašević et al. (2018) and the short overview on the commons by Massimo De Angelis and David Harvie (2014).

Another issue is that the workshop is all about a depletable resource, which poses extra pressure on the community. This is a tough condition for the commons to flourish in and, in most cases of proper commons-based management, the resource is either stable or regenerating. Is there a threshold of scarcity in order for one to be able to co-manage a resource, and how can one trace it? This is the reason why both games usually end before there is only one chair left. Moreover, an idea of organising another version of the game where the resources gradually increase is considered. Can we co-manage our resources even when we have plenty of them, or do solidarity and conviviality flourish only in conditions of scarcity?

Scarce chairs simulate the case of natural commons, while immaterial resources like culture, information or knowledge are often considered non-excludable, non-rival or even anti-rival. Can we create a version of musical chairs and case studies that will simulate 
cases of digital commons? How can we simulate the experience of sharing a non-rival resource? A resource that is strengthened when its users increase, for example as in the case of information and knowledge-sharing, has different intrinsic characteristics and management processes than the tangible natural commons (for a detailed description see Bauwens, Kostakis and Pazaitis 2019; Arvidsson et al. 2017; Arvidsson 2020). In musical chairs, the element of music is anti-rival - the more people listen to it, the more value it gets - but how can players manage music as a commons? Another idea is that in the case study of the energy cooperative, communities can have a digital app that will facilitate the sharing of the resource, for example an open-source smart grid app which will be developed and managed by the community. In such a scenario, natural commons and knowledge commons would have to be combined in a creative synthesis of management rules.

The second part of the workshop, where the introduction of theories about the commons takes place, should include a greater variety of thinkers, theorists and activists about the commons than Ostrom's contribution alone. Additionally, in the case studies stage, working groups could be asked to form capitalistic and commons-based rules and then to compare and reflect upon those rules. Money could be introduced to both versions of the game (e.g. someone with 'money' could buy extra chairs) and participants could thus reflect on whether/how money can change the dynamics of the concepts. Does the concept of currency exchange shift the rules of managing resources or do rules define the use of money? (This might be an important exercise for experienced commoners and activists.) Another case may be the assignment of secret roles to some of the community members. For example, a person could be given the role of the president of an association, giving priority to members' access to the resources. How do identity issues shift the way we act in commons-based management?

Another idea that was proposed by participants was to create two groups: some are humans and some are bears of the North Pole. Humans have chairs and bears stand on sheets of paper that represent ice. In each round, a piece of paper is 'melting' and removed. The group of humans has the capability to ask for extra chairs, but if they do so, more 'ice' will be melted from the bears' group. In this case, the sense of community expands to non-human beings and on a global scale. Do we feel differently when we have to share among humans than when we have to share with other, distant creatures like polar bears? How important is distance, personal contact, species proximity, community sense; and consequently how do they affect the practice of sharing?

Moreover, a possible addition to the workshop is to video record the participants (with their consent) during the first two stages and screen parts of the video footage during the final reflection. The body language between the two versions of the game is so strikingly different (intense vs. relaxed) that such a task would be strongly educative. However, the potential behaviour change or discomfort that some participants might feel knowing that they are filmed prevented me from trying this idea, even if it would help to develop knowledge about the commons by interpreting the visual choreography of our childhood game.

\section{Concluding Remarks}

The framework of this workshop is concretised through an experiential style of learning that uses a childhood's game and a reflection process that is based on a variation of Kolb's four-stage interaction. Thus, learners are continuously transforming experience into a learning process through reflection. Participants enter the learning cycle first by being introduced to the musical chairs game probably known from their childhood and then practice an alteration of the game's rules towards a commons-based logic. During 
this process, participants are asked to consciously act and reflect on their experience. Next, participants are introduced to theories about the commons. Then, in a shift from thinking to doing once more, they are challenged to co-create commons-based rules for real-life case studies about sharing a resource. What seems to create deep learning outcomes is the association of the ways participants cope with sharing during the musical chairs game and deal with creating collective rules during the case studies exercise. Under this process, people both empathise and rationalise on concepts of commons, building an educational experience of what being a member of a commons-based community could feel like. This is the point where the embodied (and therefore mostly unconscious) lived experience becomes conscious through the reflection process. Thus, merging non-formal education with Kolb's cycle entails powerful educational dynamics.

Regarding the power that games may have, as Illich points out, when physical education games are performed in "warlike tournaments" they "reinforce the competitive nature of schools" $(1971,35)$ and transform "playfulness into competition" $(1971,36)$. Contrastingly, games like this workshop, when used to build "awareness of the fact that formal systems are built on changeable axioms and that conceptual operations have a gamelike nature", can "provide a unique way to penetrate formal systems" $(1971,35)$. Going further, we may ask: would societies based on other values have different games, and how can we envision such games? According to Yates $(2015,1)$ some of the processes that characterise prefigurative politics include the collective experimentation and creation of new social norms. The intention to create a new society "in the shell of the old" characterises the prefigurative strategy that "directly implements the changes one seeks" (Leach 2013, 1). Thus, creating alternatives inside everyday activities (Yates $2015,13)$ brings to some extent the future we envision into this very present. Many contemporary commons-based initiatives can be characterised as prefigurative, for they challenge the dominant narrative of how societies should function and build alternative ways in the present.

According to Pechtelidis and Kioupkiolis, the educational commons is a vibrant pedagogical process that creates new forms of subjectivities which are based on horizontal relationships and collaboration. If, as Foucault (1980) says, the subject is a product of power relations, then new forms of subjectivities based on the commons can challenge power relations (Pechtelidis and Kioupkiolis 2020, 4). In a commons-based society, we could envision that exclusion-based, competitive games will be the exception and not the rule. Instead, inclusion-based, collaborative games will emerge, reflecting a "commonly shared moral conception of the ideal society" (O'Neill 2016, 2). We cannot learn to be collaborative through competitive games; thus we need to change the underlying concepts of our teaching and our educational workshops and create the conditions to experience new knowledge, norms and practices through a prefigurative commons-based education.

This workshop is significantly enriched by various comments and feedback that was sent to the author, as it has been shared freely since March 2019 as an online document and through the web-based platform of Peer to Peer University (P2PU 2020a), a grassroots network created by librarians and community organisers that "seeks to create and sustain learning communities in public spaces around the world" (2020b). We consider this to be an effort for prefigurative education both in terms of content, by seeking to create transformative commons-alike experiences, and in terms of form, by sharing the knowledge through open and peer-to-peer means.

However, various constraints are present, and this educational concept, being a commons itself, calls for more experimentation and improvement, as it can form a 
stepping stone for live and powerful understanding of classical commons theories as well as opening up an experiential practice for contemporary radical commons.

We hope that this workshop will be experienced, implemented and enriched by many more facilitators, educators and practitioners. We also hope that many more people will reach a rooted perception that the commons is not the fairy tale of an older time but an inclusive way for building vibrant, healthy societies. Finally, we hope that the underlying educational philosophy of this workshop will spark more fascinating educational processes within the curriculum of universities and, also, outside them.

\section{References}

Ackermann, Edith. 2001. Piaget's Constructivism, Papert's Constructionism: What's the Difference?. Future of Learning Group Publication 5 (3): 438. Accessed July 8, 2020. https://learning.media.mit.edu/content/publications/EA.Piaget\%20 \%20Papert.pdf

Arvidsson, Adam. 2020. Capitalism and the Commons. Theory, Culture \& Society, 37(2): 3-30. Accessed July 8, 2020. https://doi.org/10.1177/0263276419868838

Arvidsson, Adam, Alessandro Caliandro, Alberto Cossu, Maitrayee Deka, Alessandro Gandini, Vincenzo Luise, Brigida Orria and Guido Anselmi. 2017. Commons Based Peer Production in the Information Economy. Academia.edu [website]. Accessed July 8, 2020.

https://www.academia.edu/29210209/Commons Based Peer Production in the Informatio n Economy.

Baur, Ivo, Karina Liechti, Claudia R. Binder. 2014. Why do Individuals Behave Differently in Commons Dilemmas? The Case of Alpine Farmers Using Common Property Pastures in Grindelwald, Switzerland. International Journal of the Commons 8 (2): 657-685. Accessed July 8, 2020. http://doi.org/10.18352/ijc.469

Bauwens, Michel and Vasilis Kostakis. 2014. From the Communism of Capital to Capital for the Commons: Towards an Open Co-operativism. tripleC: Communication, Capitalism \& Critique 12 (1): 356-361. Accessed July 8, 2020. https://doi.org/10.31269/triplec.v12i1.561

Bauwens, Michel, Vasilis Kostakis and Alex Pazaitis. 2019. Peer to Peer: the Commons Manifesto. London: University of Westminster Press. Accessed July 8, 2020. https://doi.org/10.16997/book33

Bollier, David. 2014. Think Like a Commoner: A Short Introduction to the Life of the Commons. Gabriola Island: New Society Publishers.

Bollier, David and Silke Helfrich. 2019. Free, Fair, and Alive: The Insurgent Power of the Commons. Gabriola Island: New Society Publishers.

Blikstein, Paulo. 2013. Digital Fabrication and "Making" in Education: the Democratization of Invention. In FabLabs: Of Machines, Makers and Inventors, edited by Julia Walter-Herrmann and Corinne Büching, 1-21. Bielefeld: Transcript Publishers. Accessed July 8, 2020. https://pdfs.semanticscholar.org/da42/02df25a6085772f565d54c5aee6da6e6e1dd.pdf

Cavallo, David. 2000. Emergent Design and Learning Environments: Building on Indigenous Knowledge. IBM Systems Journal 39: 768-781. Accessed July 8, 2020. https://doi.org/10.1147/si.393.0768

De Angelis, Massimo and David Harvie. 2014. The Commons. In The Routledge Companion to Alternative Organizations, edited by Martin Parker, George Cheney, Valérie Fournier and Chris Land, 280-294. Abingdon: Routledge.

Dewey, John. 1997. Experience and Education. New York: Free Press.

Dib, Claudio Zaki. 1988. Formal, Non-formal and Informal Education: Concepts/Applicability Cooperative Networks in Physics Education. In Cooperative Networks in Physics Education Conference Proceedings 173: 300-315. New York: American Institute of Physics.

Foucault, Michel. 1980. Two lectures. In Power/knowledge. Selected Interviews and Other Writings 1972 - 1977, edited by C. Gordon, 78-108. New York: Pantheon Books.

Freire, Paulo. 2000. Pedagogy of the oppressed (30th anniversary edition). New York: Continuum. 
Freire, Paulo, Patrik Clarke, Donaldo Macedo and Stanley Aronowitz. 2001. Pedagogy of Freedom: Ethics, Democracy and Civic Courage. Lanham: Rowman \& Littlefield.

Illich, Ivan. 1971. Deschooling Society. New York: Harper \& Row.

Kamat, Jyotsna. 2009. Education in Karnataka through the Ages. Kamat Research Database. Accessed July 8, 2020. http://www.kamat.com/database/books/kareducation/index.htm

Kioupkiolis, Alexandros. 2019. The Common and Counter-Hegemonic Politics: Re-thinking Social Change. Edinburgh: Edinburgh University Press.

Kohler, Richard. 2008. Jean Piaget. Continuum Library of Educational Thought, v. 12. London: Continuum International Pub. Group.

Kohonen, Viljo. 2012. Learning to Learn through Reflection: An Experiential Learning Perspective. Research Paper. University of Tampere. Accessed July 8, 2020. http://archive.ecml.at/mtp2/Elp tt/Results/DM layout/00 10/05/Supplementary\%20text\%20E. pdf

Kolb, Allen David. 2015. Experiential Learning: Experience as the Source of Learning and Development [2nd edition]. Upper Saddle River: Pearson Education, Inc. Accessed July 8, 2020. http://ptgmedia.pearsoncmg.com/images/9780133892406/samplepages/9780133892406.pdf

Kostakis, Vasilis and Stelios Stavroulakis. 2013. The Parody of the Commons. tripleC: Communication, Capitalism \& Critique 11 (2): 412-424. Accessed July 8, 2020. https://triplec.at/index.php/tripleC/article/view/561/678

Kostakis, Vasilis, Andreas Roos, Michel Bauwens. 2016. Towards a Political Ecology of the Digital Economy: Socio-environmental Implications of two Value Models. Environmental Innovation and Societal Transitions 18, 82-100. Accessed July 8, 2020. https://doi.org/10.1016/i.eist.2015.08.002

Leach, Darcy K. 2013. Prefigurative Politics. In The Wiley-Blackwell Encyclopedia of Social and Political Movements, edited by David A. Snow, Donatella Della Porta, Bert Klandermans, and Doug McAdam. Oxford: Blackwell Publishing Ltd. Accessed July 8, 2020. https://doi.org/10.1002/9780470674871.wbespm167

Mattei, Ugo. 2012. First Thoughts for a Phenomenology of the Commons. In The Wealth of the Commons: A World Beyond Market and State, edited by David Bollier and Silke Helfrich, 3744. Amherst: Levellers Press.

McCabe, Hugh. 2018. Civil War: A Board Game as Pedagogy and Critique. Studies in Health Technology and Informatics 256: 643-651. Accessed July 8, 2020. http://ebooks.iospress.nl/volumearticle/50616

Ngaka, Willy, George Openjuru and Robert E. Mazur. 2012. Exploring Formal and Non-formal Education Practices for Integrated and Diverse Learning Environments in Uganda. International Journal of Diversity in Organisations, Communities and Nations 11 (6): 109-122. Accessed July 8, 2020. https://doi.org/10.18848/1447-9532\%2Fcgp\%2Fv11i06\%2F39059

O'Neill, John. 2016. Social Imaginaries: An Overview. In Encyclopedia of Educational Philosophy and Theory, edited by Michael Peters. Singapore: Springer Singapore. Accessed July 8, 2020. https://doi.org/10.1007/978-981-287-532-7 379-1

Ostrom, Elinor. 1990/2015. Governing the Commons: the Evolution of Institutions for Collective Action. Cambridge: Cambridge University Press. Accessed July 8, 2020. https://doi.org/10.1017/CBO9781316423936

Padula, Alessandra. 2009. Musical Chairs. In Encyclopedia of Play in Today's Society, edited by Rodney P. Carlisle, 410-411. Los Angeles: SAGE.

Papert, Seymour. 1994. The children's machine: rethinking school in the age of the computer. New York: Harvester Wheatsheaf.

Pechtelidis, Yannis and Alexandros Kioupkiolis. 2020. Education as Commons, Children as Commoners: The Case Study of the Little Tree Community. Democracy and Education 28 (1): Article 5. Accessed July 8, 2020. https://democracyeducationjournal.org/home/vol28/iss1/5 
Peer to Peer University (P2PU). 2020a. Hacking the musical chairs game: How to talk about the Commons transition in non-expert audiences? About [webpage]. Accessed July 8, 2020. https://community.p2pu.org/t/hacking-the-musical-chairs-game-how-to-talk-about-thecommons-transition-in-non-expert-audiences/3249

Peer to Peer University (P2PU). 2020b. About. Accessed July 8, 2020. https://www.p2pu.org/en/about/

Ramos, Jose. 2016. Reversing the Game of Musical Chairs: the Future of Work. Resilience. Accessed July 8, 2020. https://www.resilience.org/stories/2016-11-04/the-future-of-work/

Rath, Jan. 2000. A Game of Ethnic Musical Chairs? Immigrant Businesses and the Formation and Succession of Niches in the Amsterdam Economy. In Minorities in European Cities. The Dynamics of Social Integration and Social Exclusion at the Neighbourhood Level, edited by Sophie Body-Gendrot and Marco Martiniello, 26-43. Basingstoke: Macmillan Press.

Takata, Susan. 1997. The Chairs Game: Competition versus Cooperation: The Sociological Uses of Musical Chairs. Teaching Sociology 25 (3): 200-206. Accessed July 8, 2020. https://www.jstor.org/stable/1319395?seq=1

Tomašević, Tomislav, Vedran Horvat, Alma Midžić, Ivana Dragšić and Miodrag Dakić. 2018. Commons in South East Europe: Case of Croatia, Bosnia \& Herzegovina and Macedonia. Zagreb: Institute for Political Ecology.

van der Veer, René. 2007. Lev Vygotsky. Continuum Library of Educational Thought, v. 10. London: Continuum

Waldinger, Roger. 1987. Changing Ladders and Musical Chairs: Ethnicity and Opportunity in Post-Industrial New York. Politics \& Society 15 (4): 369-401. Accessed July 8, 2020. https://doi.org/10.1177/003232928701500401

Wentworth, Roland A. Lubienski. 1999. Montessori for the New Millennium: Practical Guidance on the Teaching and Education of Children of All Ages, Based on a Rediscovery of the True Principles and Vision of Maria Montessori. Mahwah, NJ: L. Erlbaum Associates.

Yates, Luke. 2015. Rethinking Prefiguration: Alternatives, Micropolitics and Goals in Social Movements. Social Movement Studies, 14(1): 1-21. Accessed July 8, 2020. https://doi.org/10.1080/14742837.2013.870883

Yoder, Laura S. Meitzner and Abram Bicksler. 2012. Using Institutional Arrangements to Teach Undergraduates about Commons in Thailand, and Beyond. International Journal of the Commons 6 (2): 363-385. Accessed July 8, 2020. http://doi.org/10.18352/ijc.340

You Are What You Play. 2020. Pan Intercultural Arts, Musical Chairs Game. Accessed July 8, 2020. http://www.youarewhatyouplay.co.uk/musical-chairs.html

\section{About the Author}

\section{Alekos Pantazis}

Alekos Pantazis is a Core Member of the P2P Lab, an interdisciplinary research collective focused on the commons, and a Junior Research Fellow at the Ragnar Nurkse Department of Innovation and Governance, Tallinn University of Technology. Moreover, Alekos has 20 years of involvement in international civil movements, focusing on agrarian indigenous populations and the commons. His current work focuses on the convergence of convivial technologies, commons and non-formal education. 